NBER WORKING PAPER SERIES

\title{
SUB-NATIONAL DIFFERENTIATION AND THE ROLE OF THE FIRM IN OPTIMAL INTERNATIONAL PRICING
}

\author{
Edward J. Balistreri \\ James R. Markusen \\ Working Paper 13130 \\ http://www.nber.org/papers/w13130
NATIONAL BUREAU OF ECONOMIC RESEARCH
1050 Massachusetts Avenue
Cambridge, MA 02138

May 2007

This research was sponsored by the United States International Trade Commission. The research is intended to inform current and future methodologies for policy evaluation. The research is not intended to evaluate any specific policies. Any opinions or conclusions contained herein are those of the authors, not the United States International Trade Commission or any of its individual Commissioners. We received valuable comments and suggestions from Russell H. Hillberry, Robert Koopman, William M. Powers, and participants of the 8th Annual Conference on Global Economic Analysis (GTAP conference). We also thank Lauren Davis for valuable research assistance. The views expressed herein are those of the author(s) and do not necessarily reflect the views of the National Bureau of Economic Research.

(C) 2007 by Edward J. Balistreri and James R. Markusen. All rights reserved. Short sections of text, not to exceed two paragraphs, may be quoted without explicit permission provided that full credit, including $(\odot$ notice, is given to the source. 
Sub-national Differentiation and the Role of the Firm in Optimal International Pricing Edward J. Balistreri and James R. Markusen

NBER Working Paper No. 13130

May 2007

JEL No. F1,F13

\section{ABSTRACT}

We illuminate the relationship between optimal firm pricing and optimal trade policy by exploring a generalized model that accommodates product differentiation at both the national and sub-national (firm) levels. We assume monopolistic competition in the differentiated products at the sub-national level. When the national and sub-national substitution elasticities are similar we find little opportunity for small countries to improve their terms of trade through trade distortions, because firms play an important preemptive role in optimally pricing unique varieties. We contrast this with standard applications of perfect-competition Armington models, which exhibit high optimal tariffs--even for relatively small countries.

Edward J. Balistreri

Division of Economics and Business

Colorado School of Mines

Golden, CO 80401-1887

ebalistr@mines.edu

James R. Markusen

Department of Economics

University of Colorado

Boulder, CO 80309-0256

and NBER

james.markusen@colorado.edu 


\section{Introduction}

A common feature in many trade-policy applications is the Armington (1969) assumption of national product differentiation. Brown (1987) critiques these applications, questioning the validity of simulated liberalizations that result in very large adverse terms-of-trade effects for relatively small countries. We expand this critique by noting that at the calibration stage of formulating most Armington models sub-national (firm-level) product differentiation is not considered. The resulting marginal-cost pricing at the sub-national level implicitly allocates market power over unique varieties away from optimizing firms and toward the whim of the policy authority. Although pervasive in applications, this allocation of market power to countries rather than firms is a troubling departure from traditional tenets.

This study contributes to the policy simulation literature in two important ways. First, we use a generalized model of nested differentiation to illustrate the mutual consistency between traditional models of national differentiation and the large-group monopolistic competition models popular in new trade theory. Second, we identify a tension in calibration assumptions between firm-level market power and national-level international-policy leverage. Market power is conceptually observable, and is show to be an important consideration in applied welfare analysis. Assuming optimal firm-level pricing over a country's varieties can significantly reduce the implied optimal tariff.

In the past researchers have responded (at least in part) to the Brown (1987) critique of the Armington formulation by either modifying parametric assumptions, or by modifying structural assumptions. For example, McDaniel and Balistreri (2003) highlight the general view that estimated Armington elasticities are too low, and that practitioners favor higher elasticities, which imply lower optimal tariffs. Others [e.g., Brown et al. (1992)] adopt a monopolistically-competitive structure that includes firm-level differentiation and industrywide scale effects. The approach adopted here is to develop a model that maintains the 
possibility of both types of differentiation (national and sub-national). We show that the Armington and monopolistic competition structures impose specific parametric restrictions on our generalized model. ${ }^{1}$ We thus shift the focus away from alternative structures and toward potentially measurable parameters.

Our application of the generalized model contributes to the policy debate on both the theoretic and applied fronts. We show in a stylized theoretic model that increasing the degree of firm differentiation, relative to national differentiation, acts to reduce the optimal tariff. The optimal tariff remains positive when the degree of firm differentiation is less than the degree of national differentiation. ${ }^{2}$ Positive optimal tariffs under monopolistic competition are broadly consistent with the theoretic work of Flam and Helpman (1987) and Helpman and Krugman (1989). Tariffs improve a country's terms of trade regardless of whether differentiation is at the firm or at the national level, and the terms-of-trade effects of tariffs intensify when the degree of national differentiation is higher relative to the degree of firm differentiation.

We also show, however, that negative optimal tariffs are possible when the degree of firm-level differentiation is higher than the level of national differentiation. ${ }^{3}$ This result is dependent on our assumption that firm markups are based on direct competition with their domestic rivals. Although natural when firm-level differentiation is lower than national differentiation, this assumption is more tenuous when domestic varieties are more closely related to foreign varieties (relative to other domestic varieties). For example, it is natural to think of a California winery competing more closely with other California wineries. California

\footnotetext{
${ }^{1}$ In fact, the model is also general enough to accommodate the Heckscher-Ohlin-Vanek formulation. In this case we would set the firm-level and national-level elasticities of substitution to infinity.

${ }^{2}$ The relevant measure of the level of differentiation between products is the inverse of the elasticity of substitution.

${ }^{3}$ Markusen (1990) also finds that optimal tariffs might be negative when the degree of domestic differentiation in a monopolistic-competitive industry is low. That model is somewhat different from the one employed here, however, because it characterizes the role of specialized inputs in a given industry and treats all other goods as a homogeneous traded good.
} 
wineries will largely base their markup on proximity, in product space, to other California wines.

On the other hand, consider the production of aircraft. It is probably more reasonable to suppose that Boeing products and Airbus products are less differentiated than Boeing products and Lockheed Martin products (given that Lockheed Martin does not currently produce commercial aircraft). The assumption that Boeing would markup its product based on its degree of differentiation from Lockheed-Martin is logically problematic. For this reason we place a caveat on our negative optimal tariff results. From an empirical perspective, once we move to a model with multiple dimensions, commodities should probably be defined in a way that eliminates the oddity of more domestic differentiation relative to international differentiation within a given industry. For example, (Boeing) airliners should be considered a different good than military airplanes and aerospace components (produced by LockheedMartin). As with almost any empirical exercise, aggregation is not innocuous in the context of assuming markups based on the degree of domestic competition.

Another interesting result that falls out of our stylized theoretic model is that, in the presence of firm-differentiation, the optimal tariff increases as the overall degree of preference bias toward home varieties increases. This is important from the perspective of analyzing how different sets of calibration assumptions alter the policy implications. There is a great deal of missing trade in our actual observation of the trade equilibrium. ${ }^{4}$ In contrast to most theoretic models and econometric applications, simulation models accommodate missing trade via a preference bias toward home varieties. ${ }^{5}$ This bias has an effect on the optimal tariff under firm-level differentiation because it alters the relative impacts of variety changes (number of foreign versus domestic varieties) on welfare. This is an important consideration

\footnotetext{
${ }^{4}$ Trefler (1995) identifies missing trade relative to what one would expect from the theory.

${ }^{5}$ Hillberry et al. (2005) critique the over reliance calibrated models place on preference distribution parameters, and Balistreri and Hillberry (2004) illustrate the importance of home bias in a welfare analysis of the US-Canada border effect in a calibrated gravity-model application.
} 
in any policy simulation model that includes a love-of-variety formulation and calibrated preferences over regional aggregates.

On the applied front we examine the implications, and sensitivity, of our generalized demand system in a model calibrated to the Global Trade Analysis Project (GTAP) social accounts [Dimaranan and McDougall (2005)]. We examine the optimal tariff relative to global free trade for small and large countries. We generally find that optimal pricing by firms producing differentiated sub-national products acts to reduce the implied optimal tariff. We also use the model to simulate the recent U.S.-Australia Free Trade Agreement under alternative assumptions about firm differentiation. We contrast our results with other studies that examine the U.S.-Australia Free Trade Agreement.

\section{Generalized Demand System}

Figure 1 illustrates a generalized demand system for aggregating products differentiated at both the firm and national levels. Within each country or region (indexed by $r \in R$ ) traded goods are produced by monopolistic competitive firms. The composite traded good, $Q_{r}$, is a Dixit-Stiglitz aggregate of the $N_{r}$ individual firm-specific varieties, $q_{r}$. Although the varieties produced are different, we assume symmetry across the firms. Algebraically we can represent the sub-national aggregation of firm-level varieties by

$$
Q_{r}=\left[N_{r}\left(q_{r}\right)^{\alpha_{f}}\right]^{\frac{1}{\alpha_{f}}}, \text { where } \sigma_{f}=\frac{1}{1-\alpha_{f}}
$$

Throughout our analysis we adopt some simplifying assumptions about the nature of the $Q_{r}$ that are common in the literature. We assume each of the $N_{r}$ firms is small and faces an integrated world market. This indicates a simple markup over marginal cost equal to the inverse of the elasticity of substitution between firm varieties, $1 / \sigma_{f}$. Integrated markets imply 
Figure 1: Nested Demand System

\begin{tabular}{|c|c|}
\hline $\begin{array}{l}l /|| \\
\text { Firm-level Varieties: } q_{s} \\
\left(f=1, \ldots, N_{s}\right)\end{array}$ & $\begin{aligned} A_{r}: & \text { Domestic-Import } \\
& \text { composite available for } \\
& \text { use in region } r . \\
M_{r}: & \text { Composite of region- } s \\
& \text { varieties imported by } r . \\
Q_{s}: & \text { Dixit-Stiglitz composite of } \\
& \text { region-s firm-level } \\
& \text { varieties. } \\
q_{s}: & \text { Symmetric firm-level } \\
& \text { commodities produced in } \\
& \text { region } s .\end{aligned}$ \\
\hline
\end{tabular}

independence between the markup and the region in which the firm's output is ultimately consumed.

The parameter $\sigma_{f}$ can take on any value greater than one. The degree of firm-level differentiation falls as $\sigma_{f}$ increases. When $\sigma_{f}$ takes on a value of infinity then markups are zero and we have the special case of perfect competition. ${ }^{6}$ Notice that (1) simply becomes the sum of the $q_{r}$ at $\sigma_{f}$ equals infinity ( $\alpha_{f}$ approaches one as $\sigma_{f}$ approaches infinity). When $\sigma_{f}$ is finite the free-entry assumption indicates adjustments in the number of varieties such that operating profits exactly cover fixed cost payments. We also assume that all costs

\footnotetext{
${ }^{6}$ We utilize GAMS software, which accommodates assigned parameter values of +inf. In compilation GAMS automatically assigns the limits $1 /+$ inf $=0$ and $(+$ inf -1$) /+$ inf $=1$. So if we have $\sigma_{f}=+$ inf then $\alpha_{f}$ takes on a value of 1 when the program is compiled.
} 
(marginal and fixed) associated with production use inputs in the same proportion. The constant-markup formulation indicates constant firm-level output and thus no firm-scale effects. Changes in industry output are in the form of entry or exit of symmetric varieties. The love of variety nature of the Dixit-Stiglitz aggregator, however, does indicate industrylevel scale effects. For a general discussion (and critique) of these implications of the largegroup monopolistic-competition assumptions see Markusen (2002), Chapter 6.

At the national level, the demand system in a given region, $r$, is composed of a CES aggregate of the imported Dixit-Stiglitz composites and the domestic Dixit-Stiglitz composite:

$$
\begin{gathered}
A_{r}=\left[\beta_{r r}\left(Q_{r}\right)^{\alpha_{d m}}+\beta_{r}^{M}\left(M_{r}\right)^{\alpha_{d m}}\right]^{\frac{1}{\alpha_{d m}}} \text {, where } \sigma_{d m}=\frac{1}{1-\alpha_{d m}} ; \text { and } \\
M_{r}=\left[\sum_{s \neq r} \beta_{s r} Q_{s}^{\alpha_{n}}\right]^{\frac{1}{\alpha_{n}}}, \text { where } \sigma_{n}=\frac{1}{1-\alpha_{n}} .
\end{gathered}
$$

The substitution elasticity between imported varieties is indicated by $\sigma_{n}$, and the substitution elasticity between the imported composite and the domestic composite is indicated by $\sigma_{d m}$. In the case that $\sigma_{n}$ equals $\sigma_{d m}$ equation (2) simply collapses to

$$
A_{r}=\left[\sum_{s} \beta_{s r} Q_{s}^{\alpha_{n}}\right]^{\frac{1}{\alpha_{n}}}, \text { where } \sigma_{d m}=\sigma_{n}=\frac{1}{1-\alpha_{n}}
$$

It is relatively straightforward to accommodate the predominant policy-simulation models within the general demand system outlined in Figure 1. The special case of a simple constantreturns Armington formulation is accommodated by setting $\sigma_{f}$ equal to infinity (marginalcost pricing by firms) and $\sigma_{n}$ equal to $\sigma_{d m}$. Contemporary applications tend to adopt the more complex case where $\sigma_{d m}$ is some fraction — usually one half-of $\sigma_{n}{ }^{7}$

\footnotetext{
${ }^{7}$ For example, the default elasticities used in the widely applied Global Trade Analysis Project (GTAP) model employ the "rule of two," which assumes $\sigma_{n}=2 \sigma_{d m}$ [Huff et al. (1997)]. We do not intend to advocate, or perpetuate, the use of this arbitrary rule. We allow for it in our generalized system because of its prevalence in application. That said, Liu et al. (2002) fail to reject the "rule of two" as a maintained hypothesis.
} 
Another special case often adopted in the policy simulation literature is the Dixit-Stiglitz formulation of firm-level differentiation. Setting $\sigma_{f}$ equal to $\sigma_{n}$ equal to $\sigma_{d m}$ collapses the system such that only firm-level varieties are relevant. Thus by adjusting the elasticities in relation to one another we can explore different assumptions about the general nature of product differentiation at the firm and national levels. The demand system has the advantage of accommodating (parametrically) a wide variety of favored structures that are relevant in the policy forum.

\section{Illustrative General-Equilibrium Simulation Model}

The strategy for incorporating the generalized demand system in a relatively transparent simulation environment involves formulating a stylized theoretic model. The general equilibrium is formulated as a Mixed Complementarity Problem (MCP), which is computed using GAMS software. ${ }^{8}$ Following Rutherford (1999) the general equilibrium includes three sets of variables which are associated with three corresponding sets of conditions:

1. transformation activities, which generate outputs or utility, are associated with an optimality condition given the technologies;

2. prices of inputs, outputs, and composite varieties are associated with market clearance conditions; and

3. nominal income levels for each agent are associated with income balance- between the value of endowments and the value of demand.

The GAMS code for the algebraic formulation of the nonlinear MCP is presented in Appendix A. A tabular GAMS/MPSGE formulation is also available from the authors. This section is divided into two subsections. The first introduces the algebraic formulation, and the second presents the experimental controls.

\footnotetext{
${ }^{8}$ GAMS Development Corporation: http://www.gams.com.
} 
Table 1: Scope of the Stylized Theoretic Model

\begin{tabular}{|c|c|c|c|}
\hline Equilibrium Condition & (equation) & Associated Variable & Dimensions \\
\hline $\begin{array}{l}\text { 1) Optimality } \\
\text { Unit-expenditure function }=\text { True cost-of-living index } \\
\text { Unit-cost of } A_{r}=\text { The composite price index, } P A_{r} \\
\text { Unit-cost of } Q_{r}=\text { the Dixit-Stiglitz price index } P_{r} \\
\text { Marginal cost }=\text { Marginal revenue } \\
\text { Profits }=0\end{array}$ & $\begin{array}{l}(5) \\
(6) \\
(7) \\
(8) \\
(9)\end{array}$ & $\begin{array}{l}W_{r}(\text { Hicksian welfare index }) \\
A_{r}(\text { Armington activity }) \\
Q_{r}(\text { Dixit-Stiglitz Aggregate }) \\
q_{r}(\text { Firm output index }) \\
N_{r}(\text { Number of firms index })\end{array}$ & $\begin{array}{l}R \\
R \\
R \\
R \\
R\end{array}$ \\
\hline $\begin{array}{l}\text { 2) Market-Clearance } \\
\text { Labor endowment }=\text { Demand leisure }+ \text { Demand for labor } \\
\text { Supply of } q_{r}=\text { Demand for } q_{r} \text { in } Q_{r} \\
\text { Supply of } Q_{r}=\text { Domestic demand }+ \text { Export demand } \\
\text { Supply of } A_{r}=\text { Demand for } A_{r} \text { in } W_{r} \\
\text { Nominal value of welfare }\left(W_{r} \dot{P} W_{r}\right)=\text { Nominal Expenditures }\end{array}$ & $\begin{array}{l}(10) \\
(11) \\
(12) \\
(13) \\
(14)\end{array}$ & $\begin{array}{l}P L_{r}(\text { Wage index }) \\
p_{r}(\text { Price of firm-level output }) \\
P_{r}(\text { Dixit-Stiglitz price index }) \\
P A_{r}(\text { Armington price index }) \\
\left.P W_{r} \text { (True cost-of-living index }\right)\end{array}$ & $\begin{array}{l}R \\
R \\
R \\
R \\
R\end{array}$ \\
\hline $\begin{array}{l}\text { 3)Income balance } \\
\text { Nominal expenditure }=\text { Value of endowment }+ \text { Tariff revenue }\end{array}$ & $(15)$ & $R A_{r}$ (Nominal income) & $R$ \\
\hline Total Dimensions & & & $11 R$ \\
\hline
\end{tabular}

\subsection{Algebraic formulation}

The model incorporates many features designed to indicate how applied general equilibrium models might react, but also abstracts from many complications that might obscure the key effects. The model includes multiple regions/countries (indexed by $r$ ) that trade on integrated world markets. This allows us to examine experiments that vary the relative size of a region and discriminatory trade policies. Other than country size, all other aspects of each region's technology and preferences are assumed to be identical. Furthermore, we assume that each region is endowed with only one factor of production, labor $\left(L_{r}\right)$, which might be allocated to production or used directly as an input to welfare (leisure or nontraded sector). ${ }^{9}$ Thus a country's size is controlled by changing its share of the total world endowment of labor. Table 1 outlines the overall scope of the numeric model indicating the equilibrium conditions and associated variables.

We proceed by specifying the conditions outlined in Table 1. For the first condition note

\footnotetext{
${ }^{9}$ In the case with only national differentiation, the standard Armington formulation, the economy is fully specialized, and any level of tariff cannot change domestic production. We introduce the labor-leisure choice decision in order to avoid this complete specialization and inelasticity of traded output with respect to the tariff.
} 
that the unit-expenditure function indicates the marginal cost of a unit of welfare (under optimal consumption), and the welfare level will satisfy marginal cost equals marginal benefit. Let $P A_{r}$ equal the price of the composite commodity $A_{r}$ [from equation (2)], and $P L_{r}$ represent the price of labor, then assuming Cobb-Douglas utility, the equilibrium conditions associated with a welfare maximizing mix of goods and leisure are given by

$$
P A_{r}^{1-\gamma} P L_{r}^{\gamma}-P W_{r}=0
$$

where $P W_{r}$ is the true-cost-of-living index (which is the marginal benefit of an additional unit of welfare). The first term is the Cobb-Douglas unit-expenditure function. The parameter $\gamma$ indicates the value share of the non-tradable (labor) in welfare.

Associated with optimal activity levels of $A_{r}$, the activity which generates the composite of the traded commodities, are similar conditions that equate marginal cost to marginal benefit. Marginal benefit is simply represented by the price of the composite, $P A_{r}$. The unit cost of $A_{r}$ is the dual representation of the technology in (2). The arguments in this cost function include the domestic Dixit-Stiglitz composite price, given by $P_{r}$, and the gross-oftariff prices of the foreign Dixit-Stiglitz composites, $\left(1+t_{s r}\right) P_{s}$ (where $s \in R$ but $s \neq r$ ). The condition is

$$
\left[\beta_{r r} P_{r}^{1-\sigma_{d m}}+\beta_{r}^{M}\left(\sum_{s \neq r} \beta_{s r}\left[\left(1+t_{s r}\right) P_{s}\right]^{1-\sigma_{n}}\right)^{\frac{1-\sigma_{d m}}{1-\sigma_{n}}}\right]^{\frac{1}{1-\sigma_{d m}}}-P A_{r}=0
$$

Formulating monopolistically-competitive production of the Dixit-Stiglitz composite $Q_{r}$ includes three separate conditions. First there is an industry-wide condition for the $Q_{r}$ activity (where $p_{r}$ is the price charged by a representative firm);

$$
\left[N_{r} p_{r}^{1-\sigma_{f}}\right]^{\frac{1}{1-\sigma_{f}}}-P_{r}=0
$$


Equation (7) is simply the dual of the Dixit-Stiglitz aggregation presented in (1). Second, firm-level output, $q_{r}$, is determined by the optimal pricing decision (where the demand elasticity for a small firm is $\sigma_{f}$ ). Marginal cost is simply the price of labor, $P L_{r}$, and firms maximize profits by pricing according to the familiar markup;

$$
P L_{r}-\left(1-1 / \sigma_{f}\right) p_{r}=0
$$

The third condition is associated with free entry. The number of firms, $N_{r}$, is determined by the condition that entry will adjust such that profits are zero. Operating profits cover the value of fixed costs (where we denote $f_{r}$ as the fixed cost in labor units);

$$
P L_{r} f_{r}-\frac{p_{r} q_{r}}{\sigma_{f}}=0
$$

Combining conditions (8) and (9) we can derive the familiar large-group-monopolistic-competition result that firm-level output is invariant to industry scale. When $\sigma_{f}$ is finite the number of firms adjusts to ensure zero profits. ${ }^{10}$

With all of the technologies specified in conditions (5) through (9) we generate the market equilibrium conditions for each price. Each market-clearance condition sets excess demand for each commodity to zero. The market equilibrium condition for labor is given by the exhaustion of the labor endowment, $L_{r}$, on direct demand for labor in utility and on demand for labor in production. Let $R A_{r}$ indicate nominal income in region $r$ then we have the following market clearance condition:

$$
L_{r}-\gamma \frac{R A_{r}}{P L_{r}}-N_{r}\left(f_{r}+q_{r}\right)=0
$$

\footnotetext{
${ }^{10}$ As a matter of programming practicality, when $\sigma_{f}=\infty$ the index on the number of firms is fixed at one $\left(N_{r}=1\right)$ and $q_{r}$ is allowed to vary. The level of fixed costs, $f_{r}$, is calibrated based on $\sigma_{f}$ and our assumption of zero profits in the benchmark equilibrium. When $\sigma_{f}=\infty$ there is no markup, and $f_{r}=0$.
} 
The price of firm output, $p_{r}$, is determined by the firm-level market clearance condition;

$$
q_{r}-Q_{r}\left(\frac{P_{r}}{p_{r}}\right)^{\sigma_{f}}=0
$$

We must also have market clearance for the composite commodity, $Q_{r}$;

$$
\begin{aligned}
Q_{r} & -\beta_{r r} A_{r}\left(\frac{P A_{r}}{P_{r}}\right)^{\sigma_{d m}} \\
& -\sum_{s \neq r}\left[\frac{\beta_{r s} \beta_{s}^{M} A_{s}\left(P A_{s}\right)^{\sigma} d m}{\left(\left[1+t_{r s}\right] P_{r}\right)^{\sigma_{n}}}\left[\sum_{t \neq s} \beta_{t s}\left(\left[1+t_{t s}\right] P_{t}\right)^{1-\sigma_{n}}\right]^{\frac{\sigma_{n}-\sigma_{d m}}{1-\sigma_{n}}}\right] \\
& =0
\end{aligned}
$$

Notice that the rather complex export-demand term (the last term) simplifies greatly when the elasticity of substitution between national varieties equals the domestic-import elasticity (i.e., $\left.\sigma_{n}=\sigma_{d m}\right)$.

Associated with the price indexes on the Armington composites, $P A_{r}$, are the market equilibrium conditions

$$
A_{r}-(1-\gamma) \frac{R A_{r}}{P A_{r}}=0
$$

The first term is total supply of the Armington composite and the second is Cobb-Douglas demand. The final market clearance condition ensures that the nominal value of welfare equals the nominal value of representative-agent expenditures, $R A_{r}$;

$$
P W_{r} W_{r}-R A_{r}=0
$$

The variable associated with (14) is the true-cost-of-living index, $P W_{r}$. Dividing (14) by $P W_{r}$ yields the standard market balance condition in quantities. We complete the general 
equilibrium by requiring balance between expenditures and incomes:

$$
\begin{aligned}
R A_{r} & =P L_{r} L_{r} \\
& +\sum_{s \neq r}\left[t_{s r} P_{s} \frac{\beta_{s r} \beta_{r}^{M} A_{r} P A_{r}^{\sigma_{d m}}}{\left(\left[1+t_{s r}\right] P_{s}\right)^{\sigma_{n}}}\left[\sum_{t \neq r} \beta_{t r}\left(\left[1+t_{t r}\right] P_{t}\right)^{1-\sigma_{n}}\right]^{\frac{\sigma_{n}-\sigma_{d m}}{1-\sigma_{n}}}\right]
\end{aligned}
$$

Income equals the value of the labor endowment, where $L_{r}$ is the endowment quantity, plus the value of tariff revenues.

Conditions (5) through (15) specify a complete multi-region general equilibrium that incorporates the generalized demand system illustrated in Figure 1. Only relative prices are determined, however, so we remove the market clearance condition for labor in the focus region, $H$ (Home), and declare the associated price as the numeraire $\left(P L_{H}=1\right)$.

\subsection{Experimental Parameters and Calibration}

Our primary goal is to examine the effects of changing the relative elasticities, but we are also concerned with examining the interaction of these effects with changes in the first-order calibration. The first-order calibration is indicated by the CES distribution parameters $\left(\beta_{r s}\right)$ and the endowment levels $\left(L_{r}\right) \cdot{ }^{11}$ We introduce the parametric instrument $\theta_{H}$ to control relative country sizes. The size of the focus country, indicated by the index $H$, is directly controlled by $\theta_{H}$ as follows:

$$
L_{H}=\theta_{H} L^{W}
$$

where $L^{W}=100$ is the (arbitrary) world endowment of labor. For simplicity we assume that the remaining country's endowment shares are symmetric $\left(\theta_{r}=\theta_{s}\right.$, for all $r$ and $\left.s \neq H\right)$,

\footnotetext{
${ }^{11}$ The first-order calibration also depends on the value share of the nontraded sector, $\gamma$. We do not explore the models sensitivity to this parameter in this paper. We simply make the assumption that $\gamma=0.2$ in all of the experiments that follow.
} 
Table 2: Experimental Parameters for the Illustrative Model

\begin{tabular}{lll}
\hline Parameter & Description & Range \\
\hline$\sigma_{f}=\frac{1}{1-\alpha_{f}}$ & Elasticity of substitution between firm-level varieties & $1<\sigma_{f} \leq \infty$ \\
$\sigma_{n}$ & Elasticity of substitution between import varieties & $0<\sigma_{n}<\infty$ \\
$\sigma_{d m}$ & Elasticity of substitution between domestic and import varieties & $0<\sigma_{d m}<\infty$ \\
$\theta_{H}$ & Benchmark share of the focus region, H, in world endowments & $0<\theta_{H}<1$ \\
$\lambda$ & Home-bias parameter (proportional reduction in benchmark trade) & $0<\lambda<1$ \\
\hline
\end{tabular}

such that the endowment of labor is given by

$$
L_{r \neq H}=L^{W} \frac{1-\theta_{H}}{R-1},
$$

where $R$ is the total number of regions.

We also introduce the parametric instrument $\lambda$ to control the degree of home bias in preferences. The index $\lambda$ can vary from zero, indicating no bias toward home varieties, to one. If $\lambda=1$ then domestic agents only have a preference for home varieties and there is no trade. This parameter is important because it captures a feature found in many calibrated models. Normally, missing trade is accommodated (in calibrated models) by introducing a home bias in the calibrated preferences. This stands in contrast to much of the theoretic and empirical literature, which emphasizes unobserved trade or networking costs as an important impediment to trade. ${ }^{12}$ Table 2 summarizes the parameters that are utilized in our experiments.

Given the parameter values we calibrate the benchmark trade equilibrium by computing the $\beta_{r s}$ that apply for a given experiment. We first determine units by normalizing on the benchmark wage and Armington price indexes $\left(\overline{P A}{ }_{r}=1\right.$, and $\left.\bar{P} L_{r}=1\right)$ across all regions. The bar notation indicates the level a variable takes on at the benchmark calibration. We also normalize the benchmark level of firm output, $\bar{q}_{r}=1$, so the number of firms and

\footnotetext{
${ }^{12}$ Trefler (1995) highlights the observation of "missing trade" relative to what we might expect. Balistreri and Hillberry (2004) point out, that most applied general equilibrium models adopt a first-order calibration that implicitly skews preferences toward home varieties.
} 
composite output are given by:

$$
\begin{gathered}
\bar{N}_{r}=\frac{1-\gamma}{\alpha_{f}} L_{r} ; \text { and } \\
\bar{Q}_{r}=\left(\frac{1-\gamma}{\alpha_{f}} L_{r}\right)^{\frac{1}{\alpha_{f}}} .
\end{gathered}
$$

Benchmark firm-level pricing is $\bar{p}_{r}=1 / \alpha_{f}$, and the price of the composite is given directly from equation (7) above:

$$
\bar{P}_{r}=\left[\bar{N}_{r} \bar{p}_{r}^{1-\sigma_{f}}\right]^{\frac{1}{1-\sigma_{f}}}
$$

We finalize the calibration by calculating the CES weights considering the trade reduction index $(\lambda)$. For trade from $r$ to $s$ we have region $r$ 's production share (which is the same as the endowment share) scaled by the trade reduction index and the reference prices;

$$
\beta_{r s}=\frac{L_{r}}{L^{W}} \frac{(1-\lambda)}{\bar{P}_{r}^{1-\sigma_{n}}}
$$

where $r \neq s$. The domestic weight is calculated to include the sum of reduced export weights;

$$
\beta_{r r}=\left(\frac{L_{r}+\sum_{s \neq r} \lambda L_{s}}{L^{W}}\right) \frac{1}{\bar{P}_{r}^{1-\sigma_{d m}}}
$$

Finally the aggregate import weight is calculated as

$$
\beta_{r}^{M}=\frac{1-\beta_{r r} \bar{P}_{r}^{1-\sigma_{d m}}}{\left(\sum_{s \neq r} \beta_{s r} \bar{P}_{s}^{1-\sigma_{n}}\right)^{\frac{1-\sigma_{d m}}{1-\sigma_{n}}}},
$$

such that $\overline{P A} A_{r}=1$ is maintained in the case that $\sigma_{n} \neq \sigma_{d m}$. The actual computer code used to calibrate and solve the system is included as an appendix to this paper. 


\section{Results from the Illustrative Model}

The first experiments that we examine explore the impact of firm-level differentiation on the optimal tariff. Figure 2 shows the welfare curves as we vary the tariff imposed by region $H$ from $-15 \%$ to $40 \%$ under two scenarios. First we adopt a set of relative elasticities not unlike those typically adopted in standard Armington applied general equilibrium models. That is, $\sigma_{f}=+\infty$ and $\sigma_{n}=\sigma_{d m}=7$. In the second case we include firm-level differentiation, which is equal to the level of national differentiation (i.e., $\sigma_{f}=\sigma_{n}=\sigma_{d m}=7$ ). In both scenarios we set the first-order calibration at the central case, characterized by a relatively small focus region size $\left(\theta_{H}=0.001\right)$; no home bias in preferences $(\lambda=0)$; and a labor value share in welfare of $20 \%(\gamma=0.2){ }^{13}$

The curve under an assumption that $\sigma_{f}=+\infty$ confirms the finding of Brown (1987) that small-country tariffs are large under the typical Armington formulation. The optimal tariff for this relatively small country is $17 \%$. Because the country is a monopoly supplier of its export variety the optimal tariff reflects the optimal markup over marginal cost, approximately $1 /\left(\sigma_{n}-1\right)$. In contrast when we make an assumption consistent with sub-national differentiation, allocating the market power over exports to firms, the optimal tariff drops dramatically to less than $1 / 2 \%$ (a finer search reveals the optimal tariff to be about $0.4 \%$ ).

One significant contribution of our generalized demand system is that all of the intermediate cases are also available. Table 3 presents the computed optimal tariffs under different assumptions about the level of firm differentiation and country size. As one might expect the optimal tariff increases with both the level of substitution between firm varieties and the relative country size. For small countries the optimal tariff is critically dependent on the degree of firm differentiation assumed. For a country that has a relative size of $0.1 \%$

\footnotetext{
${ }^{13}$ We choose such a small focus region, because we know that in a perfectly competitive model with homogeneous goods, the optimal tariff would be zero. Thus the tariff we calculate for the Armington formulation with no sub-national differentiation $\left(\sigma_{f}=+\infty\right)$ is due entirely to national product differentiation and not to country size in Figure 2
} 
Figure 2: Welfare and tariffs with and without firm differentiation $\left(\sigma_{n}=\sigma_{d m}=7, \theta_{H}=0.1 \%\right.$, $\lambda=0$, and $\gamma=0.2)$

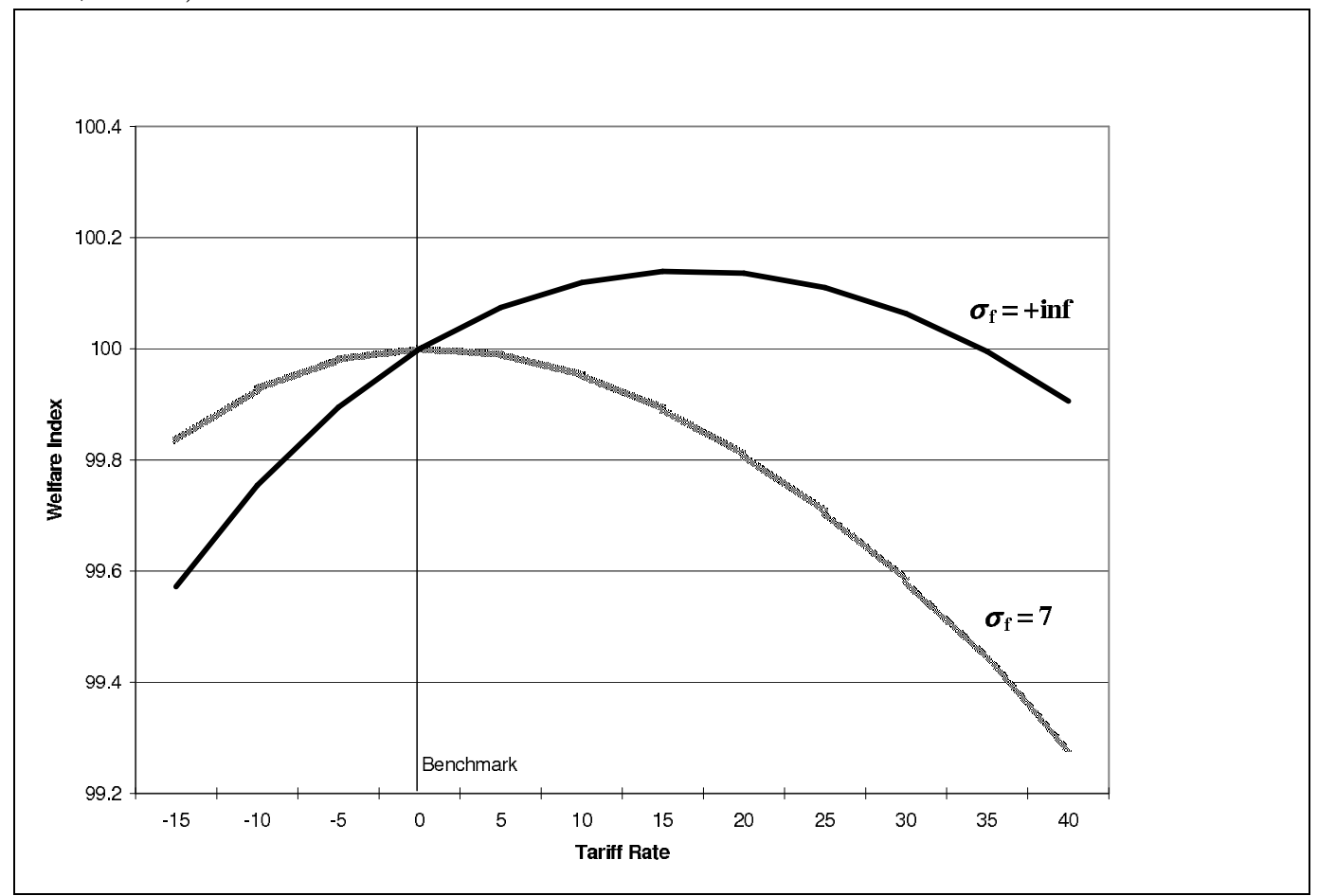

Table 3: Computed optimal tariffs in percent $\left(\sigma_{n}=\sigma_{d m}=7, \lambda=0\right.$, and $\left.\gamma=0.2\right)$

\begin{tabular}{|c|ccccccc|}
\hline & \multicolumn{7}{|c|}{$\theta_{H}$ (relative country size) } \\
\cline { 2 - 8 }$\sigma_{f}$ & $\mathbf{0 . 1 \%}$ & $\mathbf{1 . 6 \%}$ & $\mathbf{3 . 1 \%}$ & $\mathbf{6 . 3 \%}$ & $\mathbf{1 2 . 5 \%}$ & $\mathbf{2 5 \%}$ & $\mathbf{5 0 \%}$ \\
\hline $\mathbf{3 . 5}$ & -16 & -11 & -4 & 6 & 13 & 17 & 23 \\
$\mathbf{7}$ & 0 & 7 & 10 & 14 & 16 & 19 & 24 \\
$\mathbf{1 4}$ & 9 & 13 & 14 & 16 & 18 & 20 & 25 \\
$\mathbf{3 0}$ & 13 & 15 & 16 & 17 & 18 & 20 & 25 \\
$\mathbf{1 0 0}$ & 16 & 16 & 17 & 17 & 18 & 20 & 25 \\
$+\infty$ & 17 & 17 & 17 & 18 & 19 & 21 & 25 \\
\hline
\end{tabular}


of the world economy the optimal tariff ranges from a $-16 \%$ to a $+17 \%$ depending on $\sigma_{f}$. The negative optimal tariffs found for small countries with more firm differentiation than national differentiation $\left(\sigma_{f}<\sigma_{n}\right)$ are consistent with Markusen (1990).

We can think of firms as setting export taxes with their markups. In the cell $(7,0.1 \%)$, the optimal tariff is zero because the small firm's markup is aligned with a social planner's optimal export tax (given that $\left.\sigma_{f}=\sigma_{d m}\right) .{ }^{14}$ The firm's market power is based on the differentiation indicated by $\sigma_{f}$, and the (small-country's) social planner's market power is based on the differentiation indicated by $\sigma_{d m}$. When the elasticities are aligned the social planner is preempted by optimal firm pricing. In the cell $(3.5,0.1 \%)$, the export tax set by each small firm is too high given that $\sigma_{d m}=7.0$, and thus a negative optimal tariff is required as an offsetting distortion. This is the intuition about the result that moving down any column leads to an increase in the optimal tariff.

The intuition about moving across a row (in Table 3) follows from a more traditional large-country argument for optimal tariffs. Large countries have market power based on the collective size of their exporting industry on world markets. In the cell $(7,50 \%)$ home firms are optimally exploiting differentiation, but are not accounting for the fact that collectively they are one half of the world market. ${ }^{15}$ Essentially, within the industry there is an externality associated with marginal increases in firm pricing, the benefits of which accrue to all competing firms. If some of these firms are in the home country then, from a home-country social planner's perspective, firm-level mark ups are too low. This effect intensifies as we move across any given row of Table 3. As we move across the row more of the externality accrues to home firms, and higher optimal tariffs are indicated.

Figure 3 and Table 4 show the same pattern of results when we double the elasticity of

\footnotetext{
${ }^{14}$ In the general equilibrium export taxes are equivalent to import tariffs. This is commonly known as Lerner Symmetry [Lerner (1936)].

${ }^{15}$ This follows directly from our assumption that firms are small. The firm-level demand function [embedded in equation (11)] is based on each firm holding an approximately zero market share.
} 
Figure 3: Welfare and tariffs with and without firm differentiation $\left(\sigma_{n}=\sigma_{d m}=14, \theta_{H}=0.1 \%\right.$, $\lambda=0$, and $\gamma=0.2)$

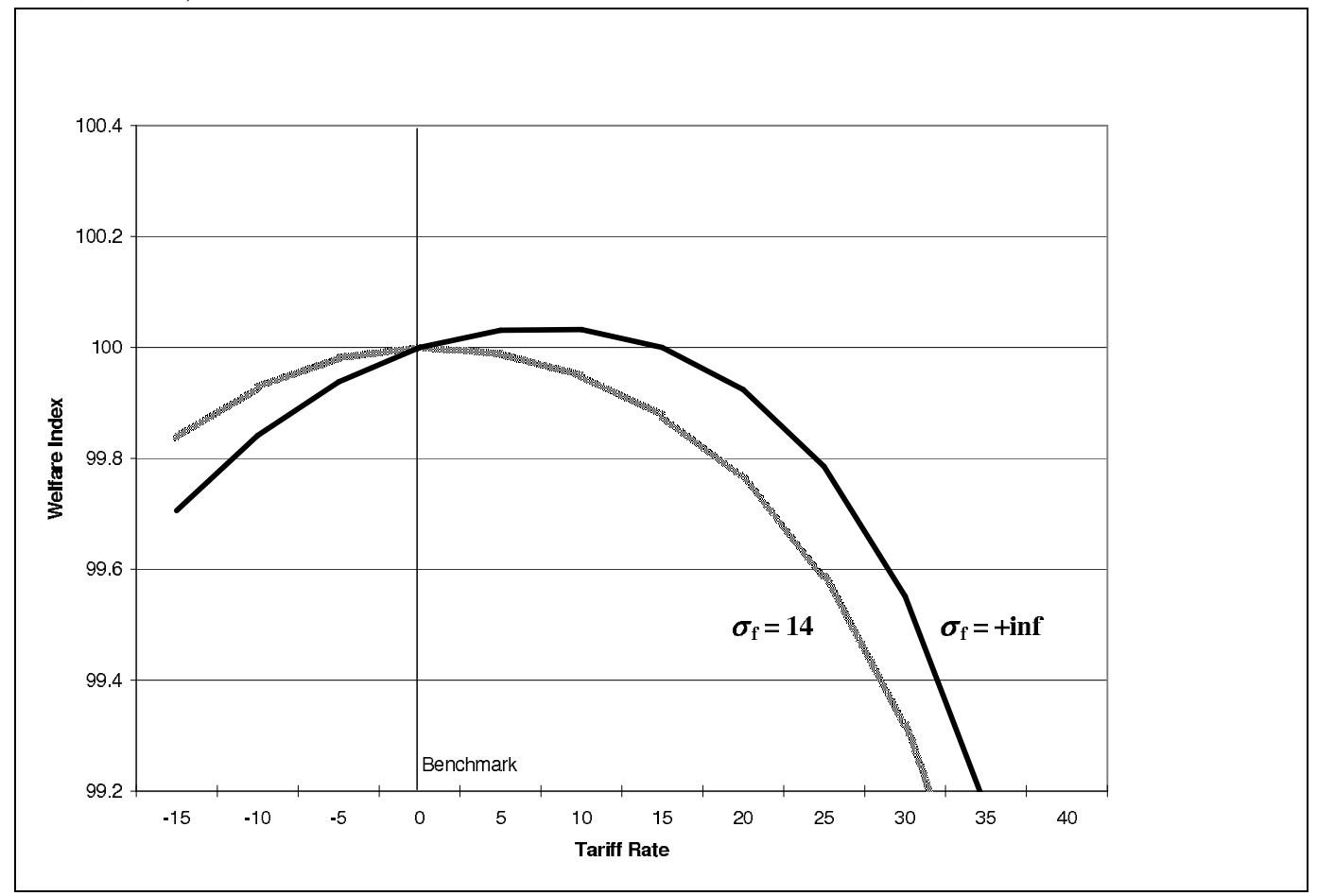

substitution between national varieties. As mentioned in our introduction one might mitigate large optimal tariffs in the Armington framework by increasing the Armington elasticity, $\sigma_{n}$. We show this implication, as the optimal tariff for the small country drops from $17 \%$ to $8 \%$ when the national-level elasticity is set to 14 rather than 7 . The key contribution that our generalized demand system offers, however, is a decoupling of the optimal tariff from the specific Armington elasticity. For small countries, allocating market power over distinct varieties to firms rather than countries centers the welfare curves in Figures 2 and 3 over an approximately zero tariff, regardless of the Armington elasticity. Armington elasticities are thus free to be set in a way that best reflects trade responses, and not as a control on the optimal tariff.

Another interesting result that emerges from our stylized theoretic model is that the optimal tariff increases as the degree of home bias increases. In Table 5 we hold the size of 
Table 4: Computed optimal tariffs in percent $\left(\sigma_{n}=\sigma_{d m}=14, \lambda=0\right.$, and $\left.\gamma=0.2\right)$

\begin{tabular}{|c|ccccccc|}
\hline & \multicolumn{7}{|c|}{$\theta_{H}$ (relative country size) } \\
\cline { 2 - 8 }$\sigma_{f}$ & $\mathbf{0 . 1 \%}$ & $\mathbf{1 . 6 \%}$ & $\mathbf{3 . 1 \%}$ & $\mathbf{6 . 3 \%}$ & $\mathbf{1 2 . 5 \%}$ & $\mathbf{2 5 \%}$ & $\mathbf{5 0 \%}$ \\
\hline $\mathbf{3 . 5}$ & -23 & -20 & -17 & -8 & 10 & 7 & 12 \\
$\mathbf{7}$ & -7 & -3 & 0 & 3 & 6 & 9 & 13 \\
$\mathbf{1 4}$ & 0 & 3 & 5 & 6 & 8 & 10 & 14 \\
$\mathbf{3 0}$ & 4 & 6 & 7 & 8 & 9 & 10 & 14 \\
$\mathbf{1 0 0}$ & 7 & 7 & 8 & 8 & 9 & 11 & 14 \\
$+\infty$ & 8 & 8 & 8 & 8 & 9 & 11 & 14 \\
\hline
\end{tabular}

Table 5: Computed optimal tariffs in percent $\left(\sigma_{n}=\sigma_{d m}=7, \theta_{H}=0.1 \%\right.$, and $\left.\gamma=0.2\right)$

\begin{tabular}{|l|rrrrrr|}
\hline & \multicolumn{6}{|c|}{$\lambda$ (trade reduction index) } \\
Higher values indicate \\
& \multicolumn{6}{|c|}{ more home bias } \\
\cline { 2 - 7 }$\sigma_{f}$ & $\mathbf{0 . 0}$ & $\mathbf{0 . 1}$ & $\mathbf{0 . 2}$ & $\mathbf{0 . 3}$ & $\mathbf{0 . 4}$ & $\mathbf{0 . 5}$ \\
\hline $\mathbf{3 . 5}$ & -16 & 9 & 12 & 13 & 14 & 14 \\
$\mathbf{7}$ & 0 & 14 & 15 & 15 & 16 & 16 \\
$\mathbf{1 4}$ & 9 & 15 & 16 & 16 & 16 & 16 \\
$\mathbf{3 0}$ & 13 & 16 & 16 & 16 & 16 & 16 \\
$\mathbf{1 0 0}$ & 16 & 17 & 17 & 17 & 17 & 17 \\
$+\boldsymbol{\infty}$ & 17 & 17 & 17 & 17 & 17 & 17 \\
\hline
\end{tabular}

the country to be relatively small, at $0.1 \%$ of world income, but increase the value of $\lambda$ from zero to 0.5 . The results in Table 5 show a dramatic increase in the optimal tariff as home bias increases, even for a relatively small country and regardless of the degree of sub-national differentiation assumed.

To explain the results in Table 5, consider beginning at a symmetric free-trade equilibrium where domestic and imported varieties are priced the same. Suppose that an import tariff leaves the total number of varieties unchanged, but leads to a substitution of domestic for foreign varieties: $d N_{H}=-\sum_{r \neq H} d N_{r}>0$. If there is home bias, this change benefits the domestic economy more than without, since the shifts are weighted by their utility value and both varieties (locally) cost the same. Conversely, the rest of the world is hurt more by this change than without home bias, because their loss of home varieties is valued more than 
the increase in imported varieties. This generalizes to a case where $d N_{H}+\sum_{r \neq H} d N_{r}<0$ in the relative sense that the welfare increase is greater, or the loss less, when there is home bias than when there is not. This process is of course bounded: as the tariff increases, each foreign variety is valued domestically (the domestic demand prices) by more than the cost of buying it (the pre-tax import prices) and so at some point the loss of a foreign variety is more welfare-costly than the gain of a domestic variety.

The pattern of results presented in Table 5 is important to the contemporary debate over unobserved trade costs. Hillberry et al. (2005) indicate that we might not need to worry about whether a calibrated model accommodates missing trade through taste bias or through unobserved trade frictions - as long as policy is independent of the unobserved trade frictions. ${ }^{16}$ Our analysis suggests that this may hold in the case of perfect competition (the optimal tariff varies little in the final row of Table 5), but when sub-national differentiation is considered the degree that the model attributes missing trade to a taste bias affects the optimal tariff.

In turn, this is an important consideration in applied welfare analysis. For example, the second row of Table 5 shows an optimal tariff of zero if we assume no taste bias but an optimal tariff of $14 \%$ for a modest amount of taste bias. When alternative methods of calibration (taste bias versus unobserved trade frictions) influence the implied optimal tariff, welfare analysis of policy will be affected.

\section{Application of the generalized model}

To give the generalized model an applied context it is useful to compare it to models that appear in the literature. To explore the performance of the generalized model we calibrate

\footnotetext{
${ }^{16}$ In fact, Hillberry et al. (2005) argue that the strong correlation between observed trade and trade frictions and the taste-bias parameters is evidence that policy is not independent of unobserved trade frictions and, therefore, we should be worried about calibrated taste bias.
} 
a version of it to the Global Trade Analysis Project (GTAP) social accounts [Dimaranan and McDougall (2005)] and conduct a number simulation experiments. The model is coded in GAMS/MPSGE and is available upon request. Although somewhat muddled by the complications of real trade patterns, the experiments tend to support our general findings (from the relatively transparent model presented above). The incentive for small countries that trade intensively (those with relatively less home bias in preferences) to unilaterally impose high rates of protection are reduced when firm-level differentiation is considered.

The overall scope of the applied model includes the world general equilibrium in multiple commodities and regions. Geographically we include four focus countries and the remainder of the world is aggregated into four regions:

- Australia

- Canada

- United States

- Chile
- Rest of America

- East Asia

- Europe

- Rest of World

The commodities in the model include the following nine aggregates:

- Agriculture

- Coal oil gas and other minerals

- Other processed food and tobacco products

- Textiles apparel and leather products

- Wood products
- Metals and metal products

- Other manufactures

- Services

- Savings good

The model uses this level of aggregation to give an indication of how an applied model might react, but also maintains a high degree of tractability. Given the methodological nature of our exercise we simply accept the GTAP data as an accurate representation of the world social accounts. Furthermore, we make no attempt at estimating actual trade elasticities. We simply make the following assumptions across each commodity. We set the elasticity of substitution between import varieties at seven $\left(\sigma_{n}=7\right)$. Consistent with many applications 
we set the domestic-import elasticity at one half the import-variety elasticity $\left(\sigma_{d m}=3.5\right)$. The key experimental control is to vary the firm-level elasticity between seven and infinity $\left(\sigma_{f}=7\right.$ or $\left.\sigma_{f}=\infty\right)$.

We start the analysis by examining the unilateral incentives for countries to impose tariffs under the alternative assumptions about firm-level differentiation. To setup the experiment we utilize an updated baseline of global free trade. Once the model is calibrated we remove all trade distortions to generate the benchmark equilibrium. This is important for looking at unilateral incentives to protect, because the observed rates of protection include product mix as well as country mix distortions.

With the free-trade benchmark established, we then identify the optimal rate of protection for a given domestic country under a uniform tariff on all imports of all commodities from all foreign countries. This will be a relatively efficient tax mechanism because it tends not to distort across commodities or source countries. Given this setup one should not be surprised to see relatively large optimal rates of protection. We warn the reader that these hypothetical experiments are designed to illustrate our argument, and should not be interpreted as policy prescriptions.

Actual tariffs on specific products (and possibly on specific products from specific countries) are inefficient relative to our experiment because they have an impact on relative prices in addition to increasing the average price. The relative price changes cause demand substitutions that are highly distortionary. In contrast, the uniform tariff that we analyze has relatively minor impacts on relative prices across commodities or on relative prices across different source regions. The uniform tariff is, therefore, relatively efficient (compared to the more common targeted protection observed in the data).

Figure 4 illustrates how Canada's welfare changes with the tariff rate under the alternative assumptions about firm-level differentiation. Relative to the global-free-trade benchmark a typical Armington model indicates that Canada's optimal uniform tariff would be $18 \%$ on all 
Figure 4: Canadian welfare under a uniform tariff relative to global free trade

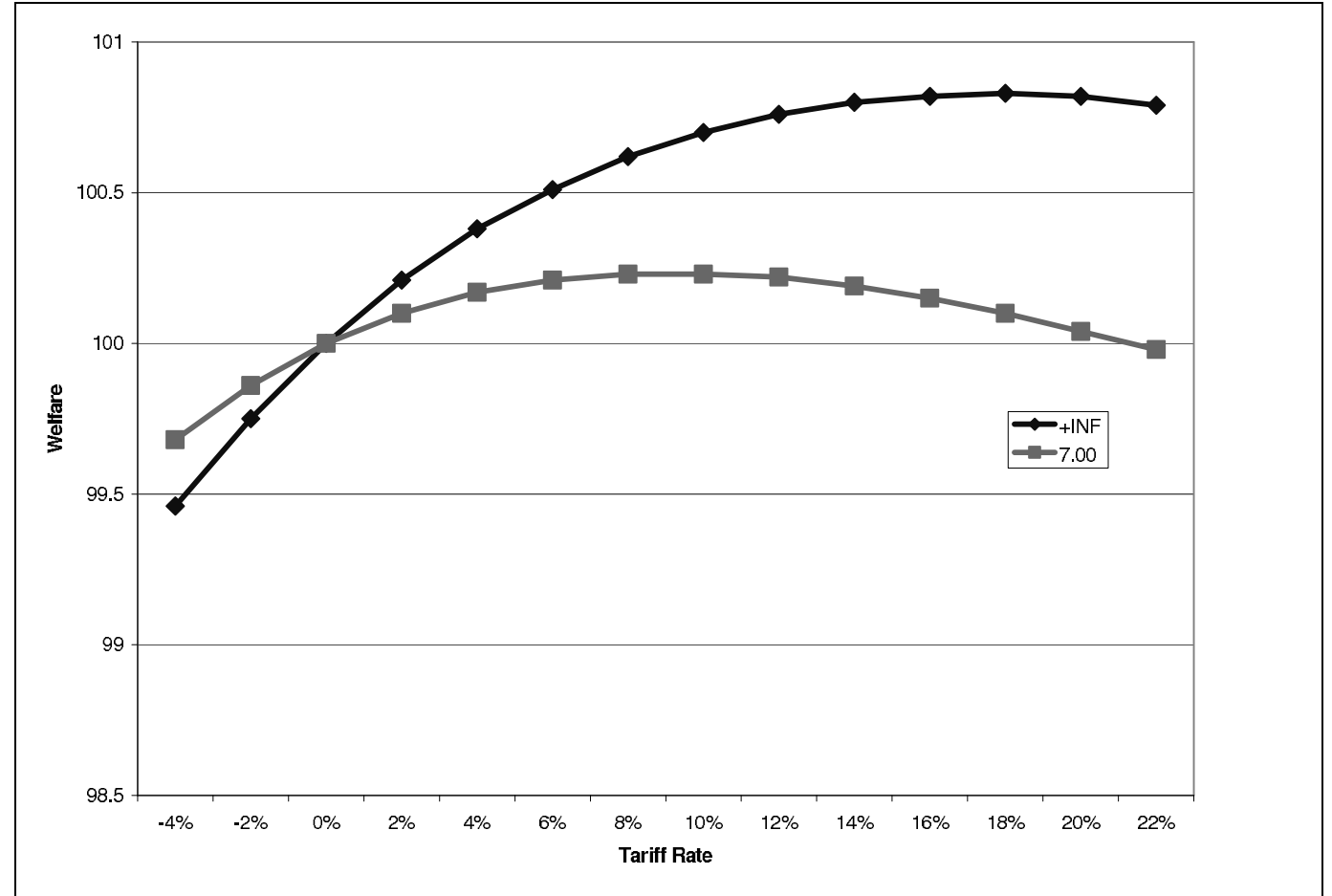

imports. In contrast, if we assume that firm varieties are also differentiated the optimal tariff is cut in half. Unlike the theoretic model presented above, however, we do not see a (nearly) complete elimination of the optimal tariff. We suggest that this is due to the presence of a home bias in the calibrated model. Considering Table 5 we can see that inserting even a modest amount of home bias in preferences escalates the optimal tariff (even when we assume a high degree of firm differentiation). So, although muted, we find general support for our hypothesis that firm differentiation is important when we examine Canada's unilateral incentives.

We find less evidence of a zero optimal tariff for Chile. Figure 5 plots the welfare curves for Chile. Under no firm differentiation the optimal tariff for Chile is $16 \%$, and this falls to $11 \%$ under firm differentiation that is equal to the level of national differentiation. Again, this points to the larger issue of home bias. If there are large networking costs, or other 
Figure 5: Chilean welfare under a uniform tariff relative to global free trade

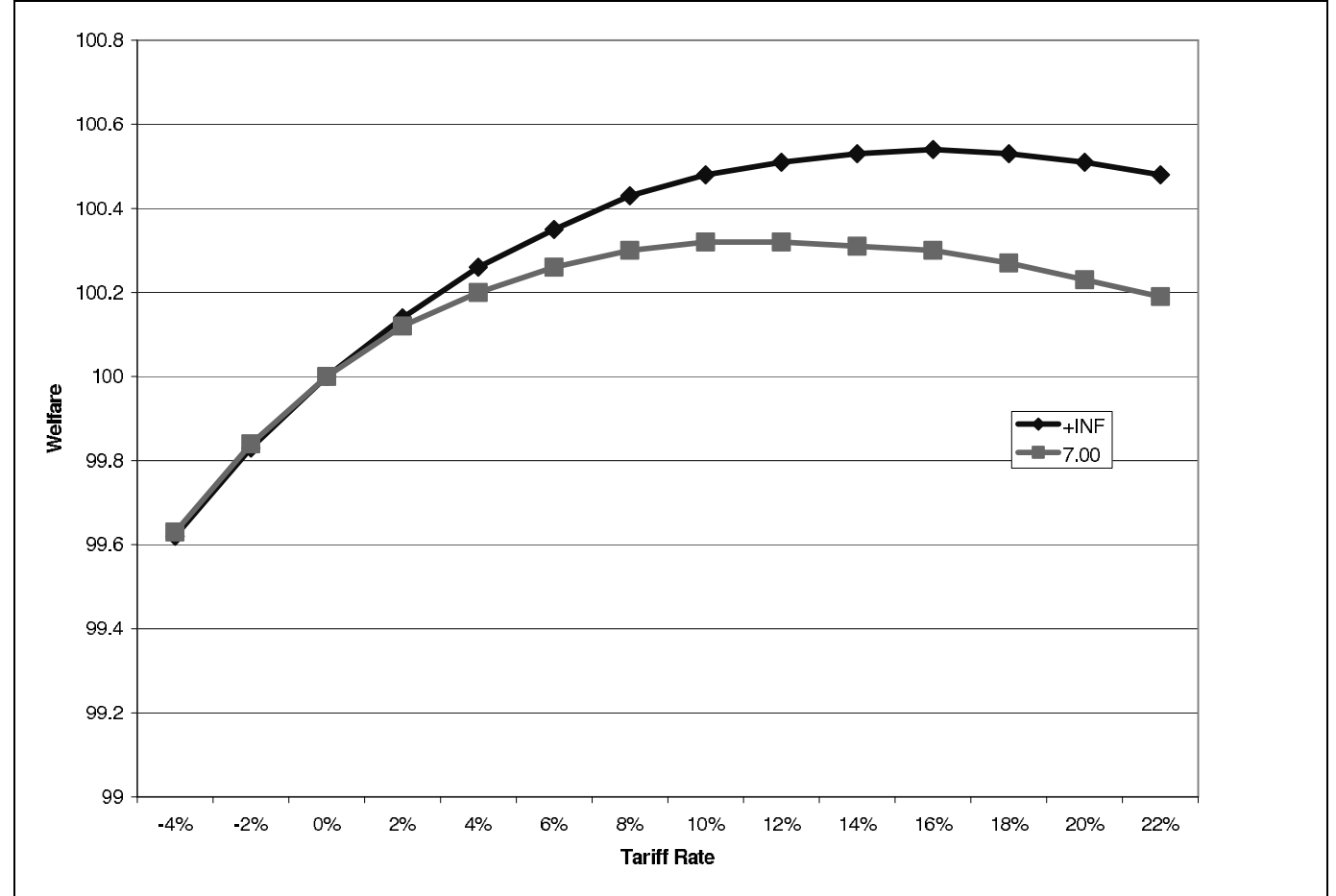

unobserved costs which restrict trade, and simulation models accommodate the observed trade flows by asserting a preference for the home variety, then the simulation models are likely to exhibit sizable optimal tariffs even for small countries, and even when we consider firm differentiation.

Given the results presented in Section 4 and knowledge of how simulation models accommodate the trade pattern, it is not surprising that the reduction of the optimal tariff is larger for Canada than it is for Chile. Canada is relatively trade intensive and less remote than Chile. Lessons from the gravity literature (in international trade) suggest that more unobserved trade costs will be associated with more remote regions. The calibrated model will systematically impose more home bias on average to those countries that are more remote. The results for Australia are similar to those for Chile, which generally support the argument that home bias is important. 
Figure 6: U.S. welfare under a uniform tariff relative to global free trade

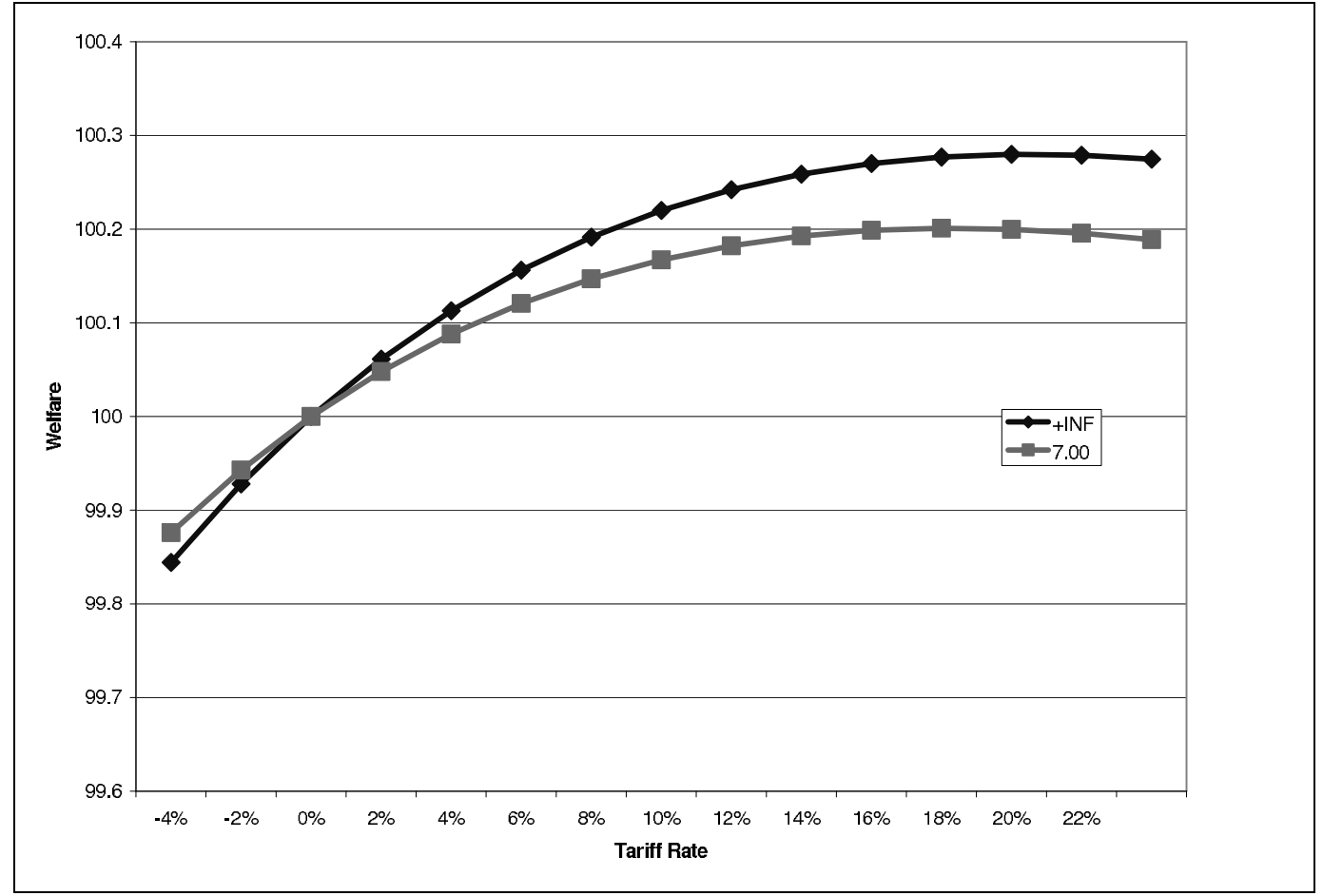

It is also useful to examine the results for the U.S. The relative size of the U.S. economy and the U.S. presence in world markets indicate that the optimal uniform tariff must be relatively high. Figure 6 plots the welfare curves for the U.S. For the U.S. the optimal rate of protection is relatively insensitive to our assumption about firm differentiation. This is consistent with the analysis in Section 4 (Table 3), where we showed that traditional large country effects dominate the firm differentiation effect at relatively modest shares of world income. The optimal tariff for the U.S. falls from $20 \%$ under the standard Armington formulation to $18 \%$ when we consider firm differentiation. This is roughly in the range of the results presented in Table 3 for an economy the size of the U.S.

To summarize our unilateral policy experiments, we find consistently smaller optimal tariffs when firm differentiation is included. This supports our overall hypothesis that firm differentiation is important. We also find, however, that in the applied model the reduction in 
optimal tariffs is not as dramatic as in our purely theoretic experiments. We suggest that this is due to the tendency for simulation models to accommodate a lack of trade to home bias. We find evidence that remoteness, which is correlated with home bias in calibrated models [Hillberry et al. (2005)], tends to reduce the impact of adding firm-level differentiation.

One additional point deserves mentioning in the context of our unilateral experiments. Notice that for each focus country that imposes a positive tariff over the relevant range, the welfare curve under no differentiation lies everywhere above the welfare curve assuming firm-level differentiation. This indicates that there is more to lose by reducing tariffs (below the optimal) when we ignore firm-level differentiation. Again this strongly supports our argument that traditional methods might understate the value of liberalization, if in fact firm varieties are important.

In addition to looking at hypothetical unilateral experiments we utilize the calibrated applied model to examine the removal of tariffs between the US and Australia. This allows us to examine the model's performance relative to applied applications that appear in the literature. We compare our results to a number of studies that have examined the likely impacts of the US-Australia Free Trade Agreement. Table 6 presents the results from four different parameterizations of our calibrated model, and selected results from three studies that appear in the literature.

The first scenario, ARM_7, is intended to give a close comparison of the pilot model to the United States International Trade Commission (2004) analysis of the US-Australia Free Trade Agreement. Aggregate results from the USITC study are reported under the column heading USITC 9090 in Table 6. In the scenario ARM_7 the pilot model adopts a national-level elasticity of substitution of 7 across all sectors and an infinite sub-national elasticity (equivalent to sub-national perfect competition). This is roughly consistent with the Armington formulation of the USITC's 9090 model. ${ }^{17}$ Thus, the model gives roughly

\footnotetext{
${ }^{17}$ There are a number of differences between the pilot calibration and simulations that we perform here
} 
Table 6: Simulating the US-Australia Free Trade Agreement

\begin{tabular}{|c|c|c|c|c|c|c|c|}
\hline & \multicolumn{4}{|c|}{ Calibrated Pilot Model } & \multirow{2}{*}{\multicolumn{3}{|c|}{ Literature Estimates }} \\
\hline & \multirow{4}{*}{$\begin{array}{r}\text { ARM_7 } \\
\sigma_{f}=+\infty \\
\sigma_{n}=7 \\
\sigma_{d m}=3.5\end{array}$} & \multirow{4}{*}{$\begin{array}{r}\text { MC_7 } \\
\sigma_{f}=7 \\
\sigma_{n}=7 \\
\sigma_{d m}=3.5\end{array}$} & \multirow{3}{*}{$\begin{array}{r}\text { ARM_30 } \\
\sigma_{f}=+\infty \\
\sigma_{n}=30\end{array}$} & MC_30 & & & \\
\hline & & & & $\sigma_{f}=30$ & & & \\
\hline & & & & $\sigma_{n}=30$ & USITC & & \\
\hline & & & $\sigma_{d m}=15$ & $\sigma_{d m}=15$ & 9090 & CIE & BKS \\
\hline Change in US & & & & & & & \\
\hline Welfare $(\$ M)$ & 885 & 629 & 972 & 1,549 & 491 & 1,231 & 19,400 \\
\hline Change in US & & & & & & & \\
\hline Total Imports & & & & & & & \\
\hline$(\$ M)$ & 1,852 & 1,777 & 21,482 & 24,630 & 1,161 & NA & NA \\
\hline Change in US & & & & & & & \\
\hline Exports to & & & & & & & \\
\hline Australia $(\$ M)$ & 2,959 & 3,005 & 29,790 & 31,724 & 2,539 & NA & NA \\
\hline Change in US & & & & & & & \\
\hline Imports from & & & & & & & \\
\hline Australia (\$M) & 2,769 & 2,954 & 32,017 & 44,356 & 1,759 & NA & NA \\
\hline
\end{tabular}

consistent results. The change in US welfare and change in US imports from Australia are lower in the 9090 study but this might be attributed to exceptions in the actual agreement that are considered in the USITC analysis, but not in our scenario. We simply remove all tariffs as measured in the GTAP data.

In the next scenario, MC_7, the model is parameterized with a national and subnational (firm-level) elasticity of substitution of 7. Adding sub-national monopolistic competition slightly reduces the US benefits from the FTA and slightly changes the aggregate trade flows. The loss in US welfare might be attributed to a reduction in foreign varieties that is and the model implemented by the United States International Trade Commission (2004). Most notably, our model simply adopts a single national-level elasticity across sectors. A national level elasticity of 7 is roughly consistent with the average of the commodity specific elasticities used by the USITC. Furthermore, our model takes the GTAP data and benchmark distortions at face value, where as the USITC 9090 model adds significant corrections and modifications. The data aggregations and scenario shocks also differ between the pilot and USITC models. To facilitate rapid diagnostics our model is more aggregated. The scenario examined in the pilot model is a complete liberalization of tariffs between the US and Australia. The USITC scenario includes detailed exceptions that were a part of the actual agreement. The simplifications made to the pilot model were made to facilitate a timely comparison and we would advise a more careful consideration of the real world in any actual simulation. That said, we feel that the results from our model are sufficiently close to the USITC's results to make a legitimate and useful comparison. 
not offset by increases in US or Australian varieties (in contrast Australian welfare impacts increase in the MC_7 case relative to the $\mathrm{ARM}_{-} 7$ case).

The next two scenarios, ARM_30 and MC_30, indicate how the pilot model responds when the national elasticity of substitution is 30 and the sub-national elasticities are respectively infinite and 30. These scenarios illustrate the problematic nature of mitigating high optimal tariffs through elasticity increases. These scenarios have similar relative results, but larger welfare benefits and extremely large trade responses. Depending on whether we look at imports or exports, the ARM_7 and $\mathrm{MC}_{-} 7$ scenarios generate bilateral trade responses in the range of $19 \%$ to $26 \%$. In contrast, moving these elasticities up to 30 generates trade responses in the range of $188 \%$ to $390 \%$ of base flows - an order of magnitude higher.

In Table 6, we also include the aggregate welfare results used by the United States International Trade Commission (2004) to compare their model with other estimates. The column titled CIE includes the welfare calculation made by the USITC based on the Berkelmans et al. (2001) study for the Center for International Economics, and the column titled BKS is the welfare estimate made by Brown et al. (2004). It is notable that although our model adopts a monopolistic competition structure it does not come close to replicating the welfare impacts reported by Brown et al. (2004). As noted in the USITC study, the Brown et al. (2004) welfare results are substantial at $85 \%$ of their reported base trade volumes with the US. ${ }^{18}$ One reason that the results of Brown et al. (2004) are larger is because they assume substantial benchmark distortions in service sectors, which vanish as a result of the FTA.

We view our demonstration of the U.S.-Australia liberalization using our generalized model as encouraging and useful. Our model generates results in the range of most standard models, but accommodates monopolistic competition elements that may be important to the measurement of potential gains from liberalization. The model offers a way of accommodat-

\footnotetext{
${ }^{18}$ Trade volume is measured as the sum of US imports from Australia plus the sum of US exports to Australia.
} 
ing the gains associated with scale and variety effects without exaggerating trade responses. The model is demonstrated to be tractable in a real policy context and allows the user the flexibility to choose any level of national and sub-national differentiation.

\section{Conclusion}

Reconciling observed intra-industry trade with policy simulation models often involves adopting an assumption of product differentiation. Most applications assume national-level differentiation with perfect sub-national competition, or alternatively, firm-level monopolistic competition and no distinction between national varieties. It is well known that these different structures produce different implied optimal tariffs. This, along with industry scale effects, means that the different structures generate different simulated impacts from liberalization. Accurate policy simulation seems to dictate a careful examination of the actual industrial organization. Ideally, with unlimited resources and time, one might develop the right structure for each industry and product.

Unfortunately, policy relevance also dictates a timely response with relatively transparent economy-wide results. Parsimony in modeling is the rule. Following the critique of Brown (1987), we caution that assuming differentiated national products, although convenient, can lead to significant implications for the welfare analysis of commercial policy. In particular, we highlight the implicit allocation of market power over distinct varieties to policy makers and away from firms. This is troubling in that, traditionally, economists assume that the agents involved in the actual transactions (exporting firms in this case) extract the rents.

To show the importance of the implicit allocation of market power we develop a generalized model that parametrically accommodates both national and firm-level differentiation. Firm-level differentiation is accommodated via a standard model of monopolistic competition. The model is parsimonious but controls the degree of market power allocated to 
countries, versus firms, on a continuum. Our theoretic exploration of this new model is limited, but we have developed some interesting results, which are important for contemporary research.

Most importantly we show that the optimal tariff falls when we make parametric assumptions that allocate market power to firms rather than countries. This is important because it indicates that many contemporary studies that adopt national differentiation, with sub-national perfect competition, might understate the true benefits of liberalization. Furthermore, we show that accommodating the trade pattern by calibrating the CES preference parameters can exacerbate the problem even when sub-national differentiation is considered. Home bias in preferences implicitly favors home varieties and, again, moves us towards relatively higher optimal tariffs. As an alternative to preference biases, the theoretic and econometric literatures emphasize unobserved trade costs in their explanation of the trade

pattern. Policy simulation models may, again, understate the true benefits of liberalization, because they calibrate in a way that implicitly indicates high optimal tariffs.

In an empirical context we highlight that the optimal tariff is most sensitive to our assumptions about firm-level differentiation for small countries and when there is relatively little home bias in the pattern of trade. We also demonstrate the generalized demand system in a pilot applied general equilibrium simulation of the US-Australia Free Trade Agreement. Moving the research forward, the theoretic implications of our generalized demand system deserve a closer examination. Through this examination we hope to highlight the important role of the firm in optimally pricing varieties on international markets.

\section{References}

Armington, P.S. (1969) 'A theory of demand for products distinguished by place of production.' IMF Staff Papers 16(1), 159-176

Balistreri, E.J., and R.H. Hillberry (2004) 'Estibration: an illustration of structural esti- 
mation as calibration.' mimeo, Colorado School of Mines, Division of Economics and Business

Berkelmans, L., L. Davis, W. McKibbin, and A. Stoeckel (2001) 'Economic impacts of an Australia-United States free trade area.' Center for International Economics, Canberra and Sydney

Brown, D.K. (1987) 'Tariffs, the terms of trade, and national product differentiation.' Journal of Policy Modeling 9(3), 503-526

Brown, D.K., A.V. Deardorff, and R.M. Stern (1992) 'A North American free trade agreement: Analytical issues and a computational assessment.' The World Economy 15, 11-29

Brown, D.K., K. Kiyota, and R. Stern (2004) 'Computational analysis of the U.S. bilateral free trade agreements with Central America, Australia, and Morocco'

Dimaranan, B.V., and R.A. McDougall (2005) Global Trade, Assistance, and Production: The GTAP 6 Data Base Center for Global Trade Analysis (Purdue University)

Flam, H., and E. Helpman (1987) 'Industrial policy under monopolistic competition.' Journal of International Economics 22, 79-102

Helpman, E., and P. Krugman (1989) Trade Policy and Market Structure (Cambridge: MIT Press)

Hillberry, R.H., M.A. Anderson, E.J. Balistreri, and A.K. Fox (2005) 'Taste parameters as model residuals: Assessing the 'fit' of an Armington trade model.' Review of International Economics

Huff, K.M., K. Hanslow, T.W. Hertel, and M.E. Tsigas (1997) 'GTAP behavioral parameters.' In Global Trade Analysis: Modeling and Applications, ed. T.W. Hertel (Cambridge: Cambridge University Press) pp. 124-148

Lerner, Abba P. (1936) 'The symmetry between import and export taxes.' Economica 3, 306313

Liu, J., C. Arndt, and T.W. Hertel (2002) 'Parameter estimation and measures of fit in a global, general equilibrium model.' Journal of Economic Integration 19(3), 626-649

Markusen, J.R. (1990) 'Derationalizing tariffs with specialized intermediate inputs and differentiated final goods.' Journal of International Economics pp. 375-383

- (2002) Multinational Firms and the Theory of International Trade (Cambridge: MIT Press)

McDaniel, C.A., and E.J. Balistreri (2003) 'A review of Armington trade substitution elasticities.' Integration and Trade 7(18), 161-173 
Rutherford, Thomas F. (1999) 'Applied general equilibrium modeling with MPSGE as a GAMS subsystem: An overview of the modeling framework and syntax.' Computational Economics 14, 1-46

Trefler, D. (1995) 'The case of the missing trade and other mysteries.' American Economic Review 85(5), 1029-1046

United States International Trade Commission (2004) 'U.S.-Australia free trade agreement: Potential economywide and selected sectoral effects.' Investigation No. TA-2104-11, USITC Publication 3697

\section{A Appendix: Illustrative Model Code (GAMS soft- ware)}

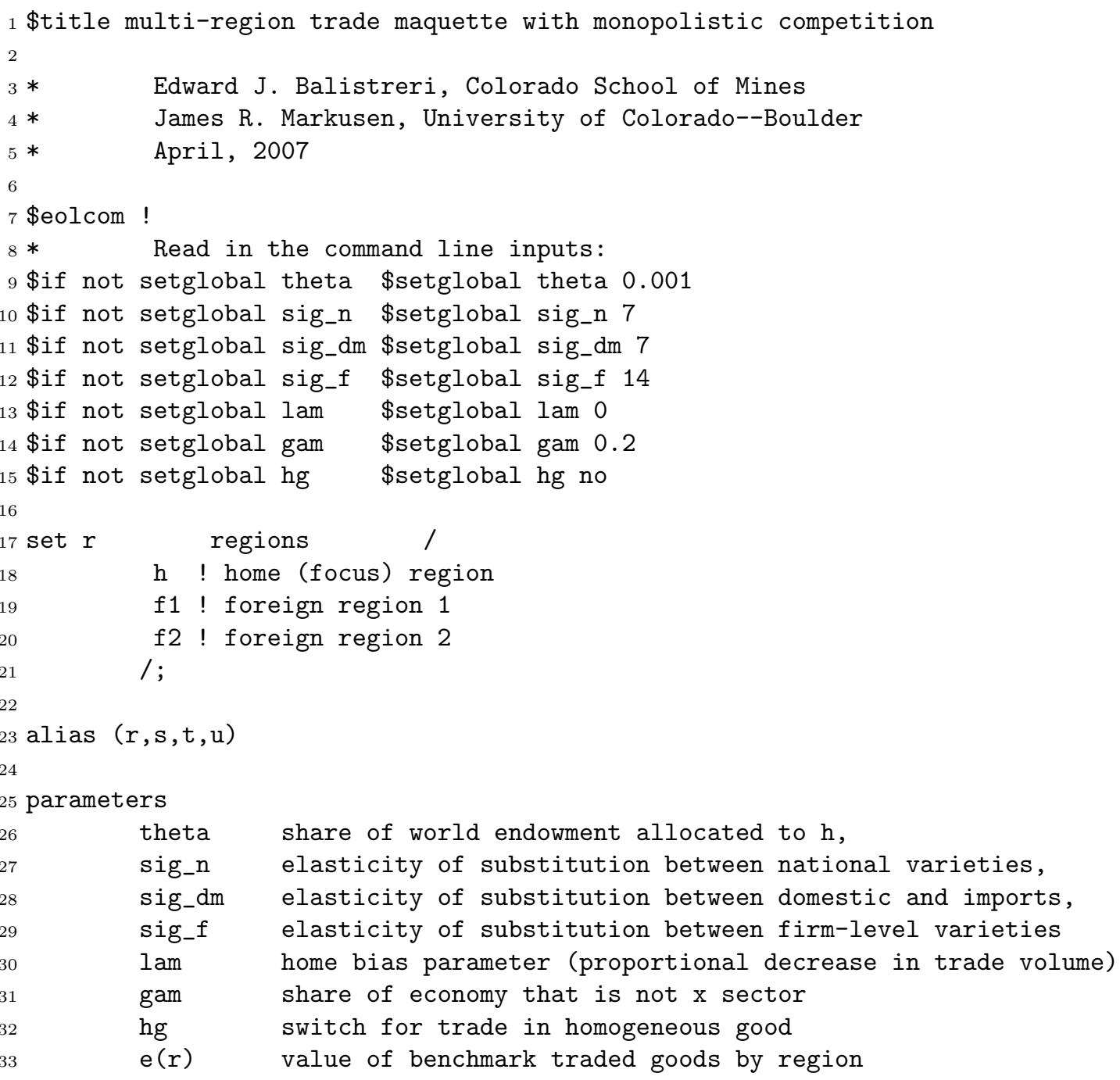




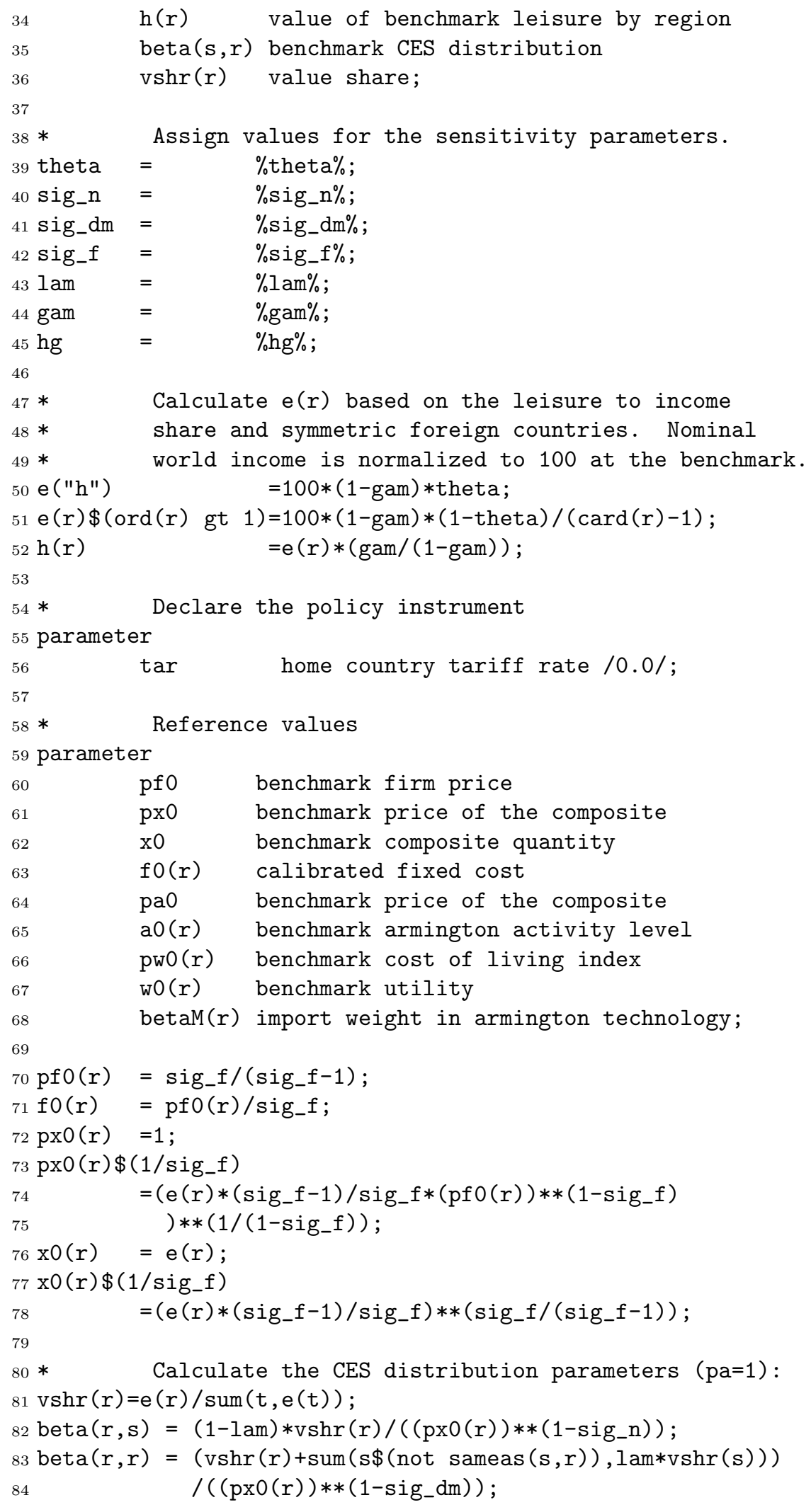




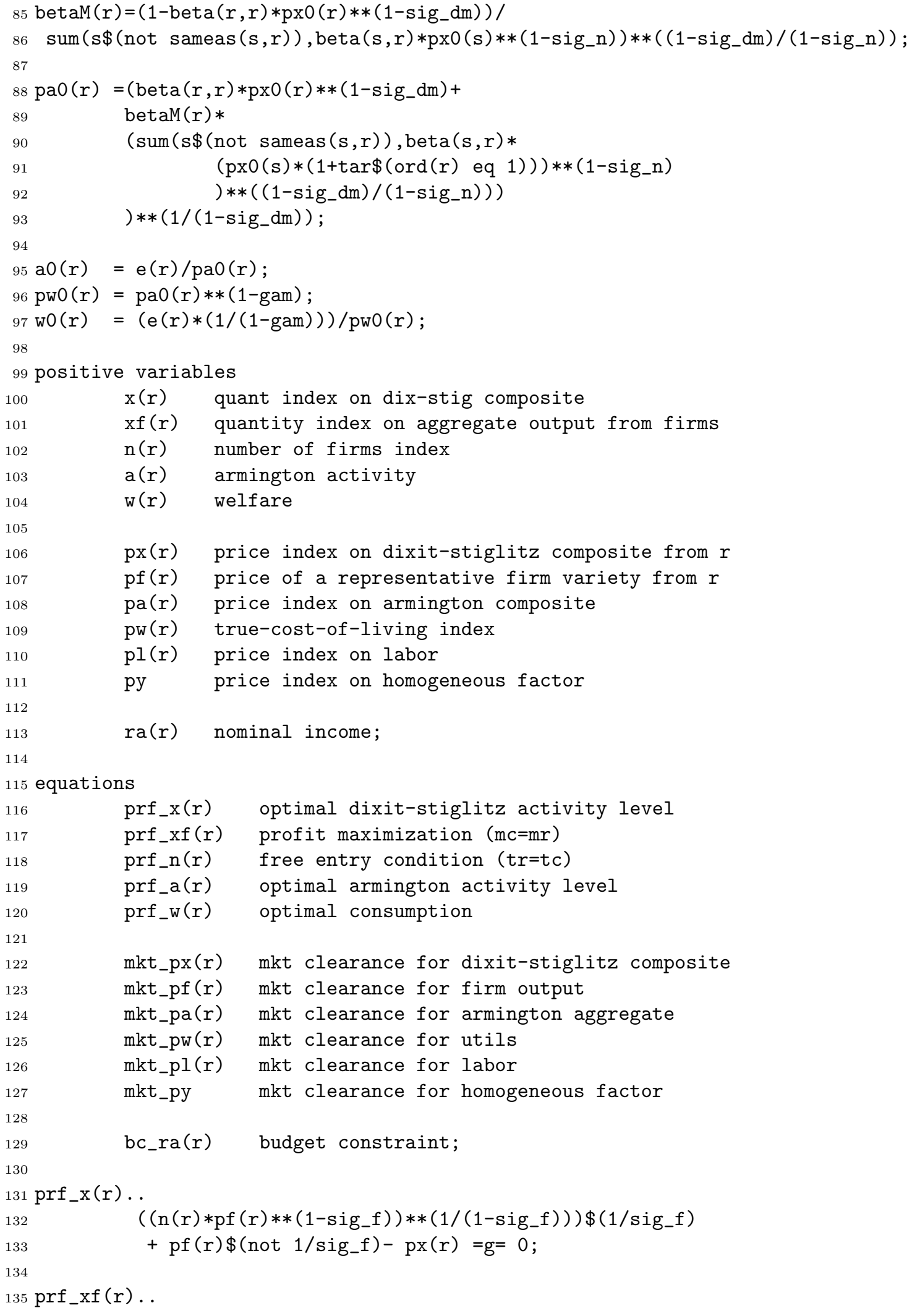




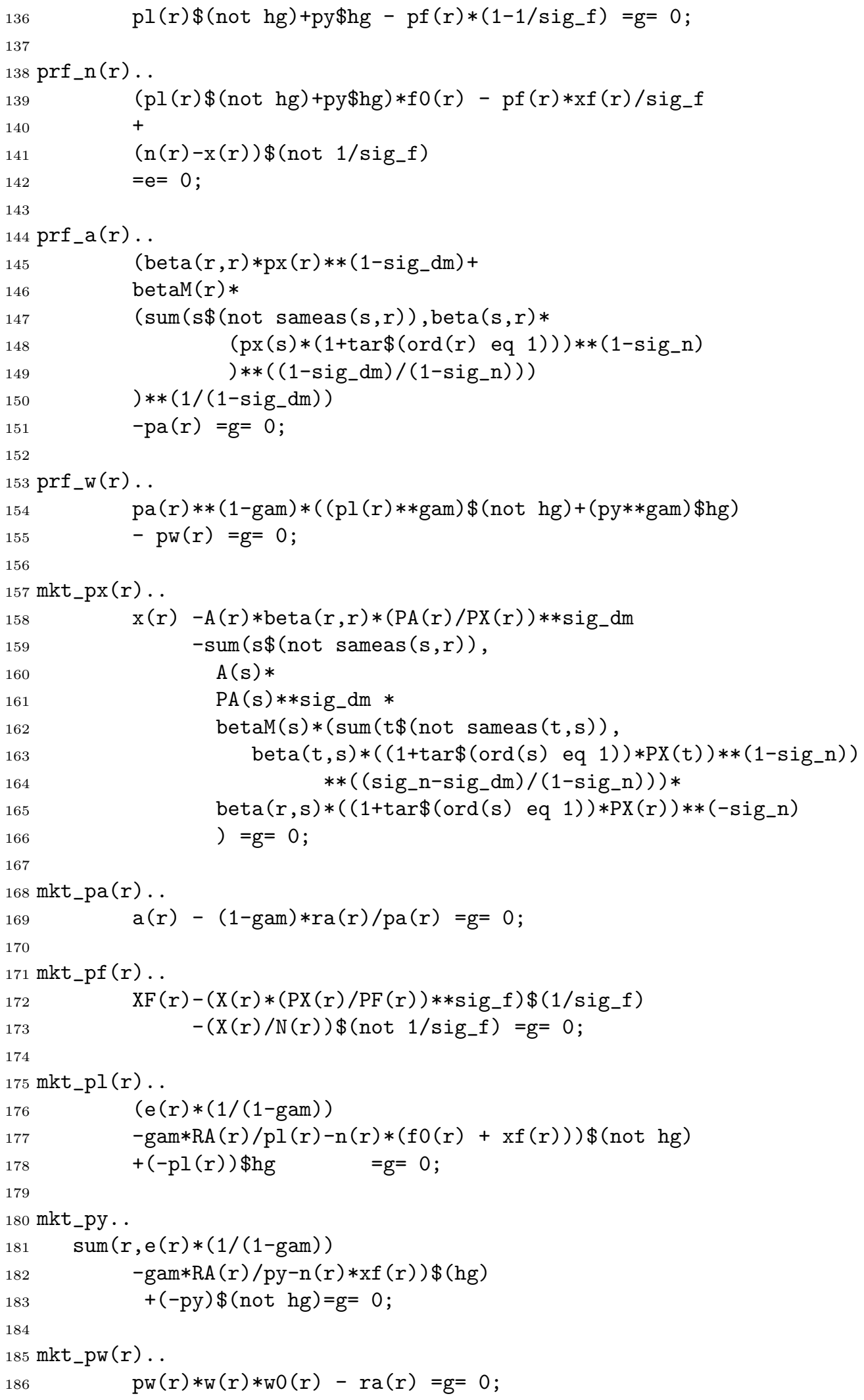


